\title{
Cost - Benefit Analysis for the Implementation of Four-arm Roundabouts in Urban Areas
}

\author{
P. Pokorný * \\ Transport Research Centre, Brno, Czech Republic \\ *Corresponding author: petr.pokorny@cdv.cz
}

DOI: 10.2478/V10158-011-0004-X

\begin{abstract}
The implementation of a roundabout has a mostly positive effect on the safety level of a treated site. This is based on the fact that the roundabout's geometry reduces the number of collision points, decreases the speed of vehicles, and improves the safety of pedestrians. Within the frame of the ROSEBUD project ${ }^{1}$, the cost - benefit analysis for the reconstruction of four-arm intersections into roundabouts has been calculated, and the results confirm that these reconstructions are effective and have positive effects on the reduction of accidents. The article describes this calculation on roundabouts in the Czech Republic.
\end{abstract}

KEY WORDS: Cost-benefit analysis (CBA), roundabout, accident reduction.

\section{INTRODUCTION}

In the Czech Republic, about $10 \%$ of road accidents occur on four-arm intersections ${ }^{2}$ [Summary of Czech accidents data, 2006 - 2009]. One of the measures aiming at reducing the number of these accidents on four-arm intersections is to rebuild the suitable intersections into roundabouts. There are several reasons for implementing the roundabouts: their effects on improving road safety and the capacity or decrease of speed (traffic calming). In some cases the roundabout can also be a significant architectonic element of a city design. The positive effects of properly designed and built roundabout are well known from numerous studies in many countries.

In Czech traffic engineering, roundabouts are still quite a new design element. There still exists some mistrust about their use. Nevertheless, the number of roundabouts in the Czech infrastructure network has significantly increased in the few last years.

There is lack of available data and studies evaluating the safety performance of roundabouts in the Czech Republic. One of the rare sources of information is the BESIDIDO project ${ }^{3}$. The accident data used in the cost-benefit analysis described below are based mainly on findings from the BESIDIDO project. The methodology of the CBA calculation was prepared in the ROSEBUD project.

1 ROSEBUD is a thematic network funded by the European Commission to support users at all levels of government (European Union, national, regional, local) with road safety related efficiency assessment solutions for the widest possible range of measures. Project deliverables can be found here http://partnet.vtt.fi/rosebud/.

${ }^{2}$ In 2009, seventy fatalities were reported in these accidents. The data are both for urban and rural roads.

3 Research project funded by the Ministry of Transport and elaborated on by CDV and Czech Technical University in Prague. Project finished in 2004 and aimed at evaluating the safety effects of various infrastructure measures. 


\section{DESCRIPTION OF THE SAMPLE}

There are eight roundabouts in the evaluated sample. The availability of relevant data and the similarity in the roundabout's design elements were the main criteria for their selection. All of them are four-arm roundabouts which were constructed between the years 1998-2002 instead of four-arm intersections in urban areas in cities with a population of less than 70000 inhabitants.
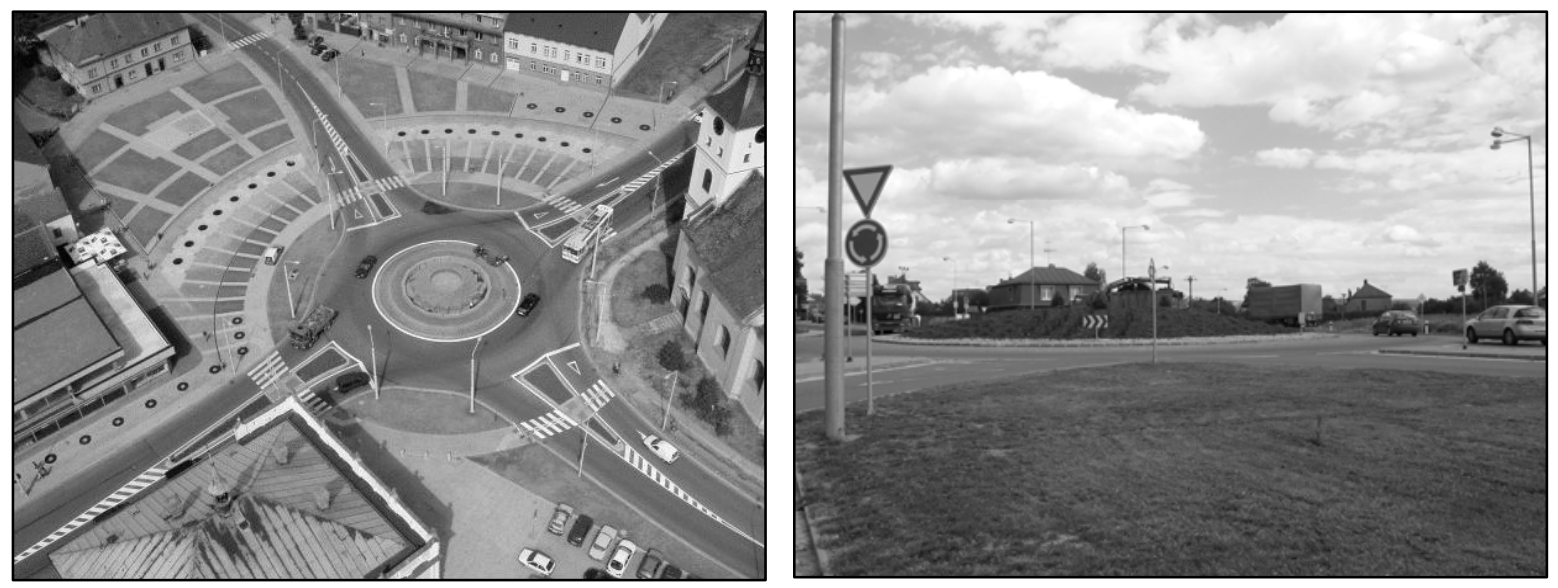

Figure1: Examples of roundabouts in the sample. On the left -Lázně Bohdaneč; on the right - Ždírec, (source: project Besidido, 2004).

A brief description of the sample is shown in Table 1.

Table 1: Description of the sample (source: project Besidido, 2004).

\begin{tabular}{|l|c|c|c|c|}
\hline \multicolumn{1}{|c|}{ Site number. City } & Population & $\begin{array}{c}\text { "Before" } \\
\text { accident data }\end{array}$ & $\begin{array}{c}\text { Year of } \\
\text { implementation }\end{array}$ & $\begin{array}{c}\text { "After" } \\
\text { accident data }\end{array}$ \\
\hline 1.Česká Lípa & 40000 & $1995-1997$ & 1998 & $1999-2000$ \\
\hline 2.Chlumec nad Cidlinou & 5000 & 2000 & 2002 & 2003 \\
\hline 3.Chrudim & 25000 & $2000-2001$ & 2002 & 2003 \\
\hline 4.Lázně Bohdaneč & 3500 & $2000-2002$ & 2003 & 2004 \\
\hline 5.Litomyšl & 10000 & $1999-2000$ & 2001 & 2002 \\
\hline 6.Most & 70000 & 1999 & 2000 & $2001-2003$ \\
\hline 7.Tábor & 37000 & $1996-1997$ & 1998 & $1999-2000$ \\
\hline 8.Ždírec & 3000 & $2000-2001$ & 2002 & $2003-2004$ \\
\hline
\end{tabular}

All roundabouts in the sample are "typical" four-arm roundabouts ${ }^{4}$ designed in accordance with the Czech technical standards. The reason for their implementation was mainly a demand for more capacity and for improving the safety situation.

\subsection{Target group of accidents}

The implementation of a roundabout has a mostly positive effect on the safety level of the treated site. This is based on the fact that the roundabout's geometry reduces

\footnotetext{
4 “Typical" means a roundabout with a one traffic circulatory lane, one-lane entrance and exit, the diameter of the roundabout is up to $35 \mathrm{~m}$.
} 
the number of collision points, decreases the speed of vehicles, and improves the safety of pedestrians. The only negative phenomena could be the lower safety level for cyclists, but only in some cases (e.g., an unsuitable design of cycle facilities). Therefore, the target accident group was defined as "all accidents occurring on the treated sites".
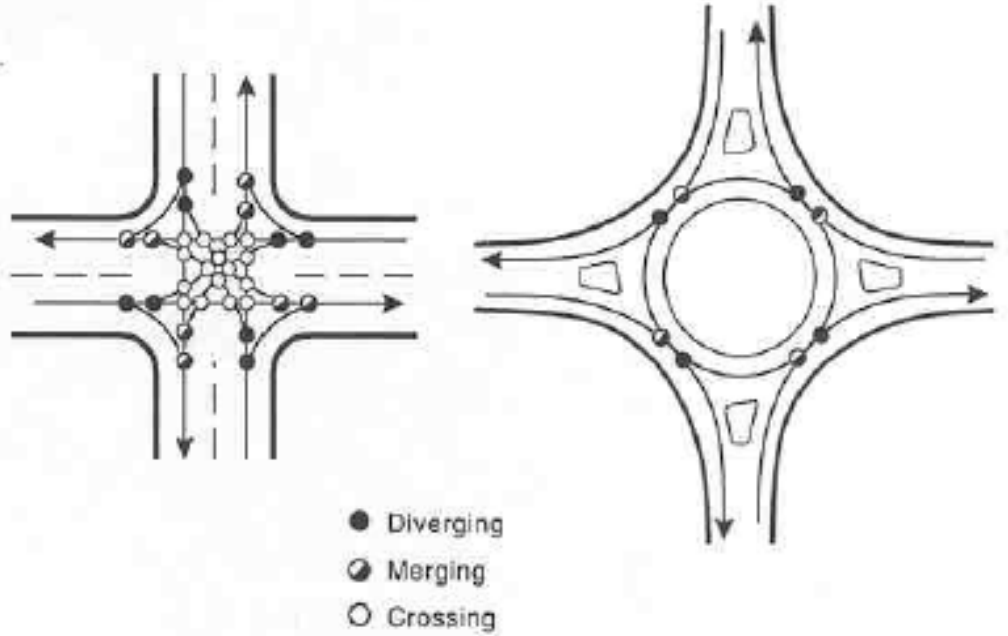

Figure2: Comparison of no. of collision points on a four-arm intersection and roundabout.

The sample contains eight sites where the original four-arm intersections without traffic lights were rebuilt into four-arm roundabouts. Based on accident data before the implementation of the roundabouts, an "average" intersection accident was determined. This is an accident with 0.004 fatality, 0.04 severely injured, 0.19 slightly injured, and with property damage valued at $27000,-\mathrm{CZK}$. The value (socio-economy loss) of one average accident is calculated to be around $7500,-€$ (at 2002 prices $^{5}$ ), based on the methodology of an accident's cost used in CDV.

\section{ASSESSMENT METHOD}

The ideal method of assessment would be to conduct a complete CBA (with a calculation of roundabout effects not only for safety performance, but also for the environment and mobility). The quality of available data did not allow for such a complete analysis, so only the safety effects were calculated in the analysis.

The suitable method for such a calculation is a method combining an after/before comparison with a control group of sites (sites which are similar in most characteristics to the treatment sites but left untreated). In this calculation, the total number of accidents on four-arm urban intersections in the whole country was used as a control group, so that the general trends in the development of accident numbers are taking into consideration.

The aim of the calculation was to find the number of accidents prevented through the implementation of roundabouts on eight sites. The "before" and "after" accident data for the treated sites and for all four-arm intersections in the Czech Republic were known.

An evaluation of the treatment effect $\theta_{\mathrm{i}}$, at each site, by means of the Odds-ratio with the comparison group, was calculated. A correction due to changes in the traffic volumes is not performed, so $\delta=1$. The formula has the form:

\footnotetext{
${ }^{5}$ This would be cca $12000,-€$ at 2009 prices
} 


$$
\text { Estimated effect }(\theta)=\frac{X_{a}}{X_{m} \frac{C_{a}}{C_{b}}} \delta
$$

where

$X_{a}$ - the number of accidents observed at the treatment site in the "after" period,

$\mathrm{X}_{\mathrm{m}}$ - the number of accidents at the treatment site in the "before" period,

$\mathrm{C}_{\mathrm{a}}$ - the number of accidents in comparison group sites in the "after" period,

$\mathrm{C}_{\mathrm{b}}$ - the number of accidents in comparison group sites in the "before" period.

Weighting the effects found for separate treatment sites is done by means of the standard method for weighting Odds-ratios, where a statistical weight of a separate result is defined by the sizes of data sets, which provided this result:

$$
\begin{aligned}
& \text { Weighted mean effect }(W M E)=\exp \left(\frac{\sum_{i} w_{i} \ln \left(\theta_{i}\right)}{\sum_{i} w_{i}}\right) \\
& w_{i}=\frac{1}{\operatorname{VAR}\left(\log \left(\theta_{i}\right)\right)}=\frac{1}{\frac{1}{X^{i}{ }_{a}}+\frac{1}{X^{i}{ }_{b}}+\frac{1}{C^{i}{ }_{a}}+\frac{1}{C^{i}{ }_{b}}}
\end{aligned}
$$

where

$\theta_{i}$ - estimate of effect for site $i$,

$\mathrm{W}_{\mathrm{i}}$ - statistical weight of estimate for site $\mathrm{i}$,

$\mathrm{X}_{\mathrm{a}}^{\mathrm{i}}$ - the number of accidents observed at treatment site $\mathrm{i}$, in the "after" period,

$\mathrm{X}_{\mathrm{b}}^{\mathrm{i}}$ - the number of accidents at treatment site $\mathrm{i}$, in the "before" period,

$\mathrm{C}_{\mathrm{a}}^{\mathrm{i}}$ - the number of accidents in comparison group (for site $\mathrm{i}$ ), in the "after" period,

$\mathrm{C}_{\mathrm{b}}^{\mathrm{i}}$ - the number of accidents in comparison group (for site $\mathrm{i}$ ), in the "before" period.

The $95 \%$ confidence interval for the weighed effect is estimated as follows:

$$
\left(W M E \exp \left(\frac{z_{\frac{\alpha}{2}}}{\sqrt{\sum_{i} w_{i}}}\right), W M E \exp \left(\frac{z_{1-\frac{\alpha}{2}}}{\sqrt{\sum_{i} w_{i}}}\right)\right)
$$

The applicable value of the safety effect, i.e., the best estimate of accident reduction associated with the treatment (in percent), is calculated as (1-WME)*100.

\section{ASSESSMENT QUANTIFICATION}

4.1 The unit of implementation, the discount rate and price of a typical accident

A four-arm roundabout was determined to be the typical unit of implementation. The typical implementation cost was estimated to be 300000 ,- $€$ (at 2002 prices). The estimate was based on results found in the BESIDIDO project. The cost of maintenance was not calculated, 
due to an assumption that the cost of maintenance is similar for four-arm intersection as it is for the four-arm roundabout. The duration of the effect was estimated to be 20 years.

The discount rate was determined to be $5 \%$. This is based on the recommended value of the discount rate used in the Rosebud project. All prices are converted into Euro, the price level is as of the year 2002. The price of a typical four-arm intersection accident was calculated to be $7500,-€$ (at 2002 prices). The calculation is based on the accident statistics of the intersections from the sample before the implementation of roundabouts.

\subsection{Safety effect}

The aim was to find the number of accidents which were prevented through the implementation of roundabouts instead of four-arm intersections in an evaluated sample of eight sites.

Table 2: Data for calculations.

\begin{tabular}{|c|c|c|c|c|c|c|}
\hline \multirow{2}{*}{$\begin{array}{c}\text { site } \\
\text { number }\end{array}$} & \multicolumn{2}{|c|}{ site accidents } & \multicolumn{2}{c|}{ comparison group } & \multirow{2}{*}{$\begin{array}{c}\text { estimated } \\
\text { effect } \theta_{\mathrm{i}}\end{array}$} & $\begin{array}{c}\text { statistical weight } \\
\text { of estimate } \mathrm{w}_{\mathrm{i}}\end{array}$ \\
\cline { 2 - 5 } before & after & before & after & 0.475 & 18.699 \\
\hline 1 & 85 & 24 & 57810 & 34356 & 1.04 & 2.5 \\
\hline 2 & 5 & 5 & 17409 & 16695 & 0.17 & 2.768 \\
\hline 3 & 36 & 3 & 34135 & 16695 & 1.178 & 3.61 \\
\hline 4 & 13 & 5 & 50861 & 16600 & 1.027 & 0.666 \\
\hline 5 & 2 & 1 & 34356 & 16726 & 0.135 & 1.428 \\
\hline 7 & 10 & 4 & 16947 & 50147 & 1.213 & 13.971 \\
\hline 8 & 27 & 29 & 38810 & 34356 & 0.054 & 0.949 \\
\hline
\end{tabular}

Table 3: Safety effect of evaluated roundabouts.

\begin{tabular}{|c|c|c|c|}
\hline $\begin{array}{l}\text { Estimated } \\
\text { effect } \\
\text { (WME) }\end{array}$ & $\begin{array}{l}\text { WME confidence } \\
\text { interval }\end{array}$ & $\begin{array}{l}\text { Number of } \\
\text { treatment sites in } \\
\text { the sample }\end{array}$ & $\begin{array}{l}\text { Number of } \\
\text { accidents at the } \\
\text { treatment sites }\end{array}$ \\
\hline 0.624 & $(0.465,0.836)$ & 8 & 197 \\
\hline
\end{tabular}

The average accident reduction associated with the treatment was calculated as $(1-\mathrm{WME}) \times 100=(1-0.624) \times 100=\mathbf{3 7 . 6 \%}$.

Table 4: Accident reduction.

\begin{tabular}{|c|c|c|}
\hline $\begin{array}{c}\text { Site } \\
\text { number }\end{array}$ & $\begin{array}{c}\text { Average annual no. } \\
\text { of accidents }\end{array}$ & $\begin{array}{c}\text { Reduction } \\
\text { of accidents }\end{array}$ \\
\hline 1 & 28.3 & 10.64 \\
\hline 2 & 5 & 1.88 \\
\hline 3 & 18 & 6.77 \\
\hline 4 & 4.3 & 1.62 \\
\hline 5 & 1 & 0.37 \\
\hline 6 & 10 & 3.76 \\
\hline 7 & 13.5 & 5.08 \\
\hline 8 & 9.5 & 3.57 \\
\hline
\end{tabular}

Total no. of saved accidents: 33.7 .

The total sum of accidents saved annually multiplied by the average accident costs (the total benefit) is $33.7 \times 7500=253000,-€$. The annual average sum of money saved for one treated site is $31625,-€$. 


\section{ASSESSMENT RESULTS}

The total cost of prevented accidents in a period of 20 years on one treated site is calculated to be $444000,-€$. Because the cost of one unit of implementation is estimated $300000,-€$, the cost/benefit ratio is $1 / 1.5$.

Table 5: Costs and benefits -20 years period.

\begin{tabular}{|c|c|}
\hline Accident saved & $444000,-€$ \\
\hline Cost of 1 unit & $300000,-€$ \\
\hline Cost $/$ benefit & $\mathbf{1} / \mathbf{1 . 5}$ \\
\hline
\end{tabular}

\section{CONCLUSION}

Due to the limited sources of available data it was not possible to calculate a complete CBA. A "mini-CBA" was thus calculated - only the safety effects of roundabouts were taken into account. The effects on environment and mobility were not taken into account. The result showed that the four-arms roundabouts in urban areas have a positive effect $(-37.6 \%)$ on the reduction of the number of all accidents.

\section{REFERENCES}

Rune Elvik and Truls Vaa. The Handbook of road safety measures. Elsevier,2004.

Chris Schoon, Jaap van Minnen, 1994. The safety of roundabouts in The Netherlands. Traffic engineering and control 3/1997, pp. 142-148.

Federal Highway Administration, (2000) Roundabouts: An Informational Guide, FHWA Report No. FHWA-RD-00-067, Turner-Fairbank Highway Research Center, McLean, VA.

Rosebud project, 2004. Improvements in efficiency assessment tools. Public deliverable.

Rosebud project, 2004. The Use of Efficiency Assessment Tools: Solutions to Barriers. Public deliverable.

The Traffic Police Directorate of the Czech Republic, the Summary of accidents data, $2002-2006$.

The Czech Statistical Office - www.czso.cz.

The Czech Ministry of Interior - www.mvcr.cz/statistiky/crv.html. 